\title{
Integrasi Pembelajaran IPS pada Kurikulum 2013 di Sekolah Dasar
}

\author{
Tika Meldina ${ }^{1}$, Melinedri $^{2}$, Alfiana Agustin ${ }^{3}$, \\ Siti Hadijah Harahap ${ }^{4}$ \\ ${ }^{134}$ Institut Agama Islam Negeri Curup \\ ${ }^{2}$ Sekolah Dasar Negeri 10 Pasaman \\ tikameldina@iaincurup.ac.id, ${ }^{2}$ melinedri@gmail.com, \\ 3alfianaagustin@gmail.com, ${ }^{4}$ sitihadijahharahap@gmail.com
}

\begin{abstract}
This research wanted to find out the integration of social studies learning in the curriculum of 2013 in elementary schools. In structure's curriculum of elementary school/ madrasah ibtidaiyah, social studies are only studied in the high class (IV, V, VI). In the low class (I, II, III) the name of the social studies is eliminated, but Basic Competence of social studies is integrated into the basic competence of other subjects such as Indonesian, Pancasila and Citizenship Education and Mathematics are linked through the closeness of meaning. In the high class, sosial studies have same position as other subjects. Even though learning is done thematically, basic competence for social studies remains independent. The approaches used in integrating social studies learning include indisciplinary, interdisciplinary and multidisciplinary integration.
\end{abstract}

Keywords : Social Studies, The Curriculum of 2013, Elementary School

Abstrak: Penelitian ini bertujuan untuk mengetahui integrasi pembelajaran Ilmu Pengetahuan Sosial (IPS) pada kurikulum 2013 di Sekolah Dasar (SD). Pada Struktur Kurikulum 2013 SD/MI, mata pelajaran IPS hanya dipelajari pada kelas tinggi yaitu kelas IV, V dan V. Pada kelas rendah nama mata pelajaran IPS ditiadakan, namun Kompetensi Dasar (KD) diintegrasikan IPS diintegrasikan ke dalam KD mata pelajaran lainnya seperti Bahasa Indonesia, Pendidikan Pancasila dan Kewarganegaraan, dan Matematika yang dikaitkan melalui keterdekatan makna. Pada kelas tinggi, IPS memiliki kedudukan yang sama dengan mata pelajaran lain. Meskipun pembelajaran dilakukan secara tematik, namun KD untuk IPS tetap berdiri sendiri. Pendekatan yang digunakan dalam mengintegrasikan pembelajaran IPS diataranya adalah melalui integrasi intradisipliner, interdisipliner dan multidisipliner.

Kata Kunci : Ilmu Pengetabuan Sosial, Kurikulum 2013, Sekolah Dasar

AR-RIAYAH : Jurnal Pendidikan Dasar Vol. 4, no. 1, 2020

IAIN Curup - Bengkulu l p ISSN 2580-362X; e ISSN 2580-3611 http://journal.iaincurup.ac.id/index.php/JPD 


\section{PENDAHULUAN}

Pendidikan semestinya sudah dilakukan sedari dini yaitu dengan melakukan pendidikan dasar. Pada Undang-undang No 20 Tahun 2003 Pasal 17 ayat 1 disebutkan pendidikan dasar merupakan jenjang pendidikan yang melandasi jenjang pendidikan menengah ${ }^{1}$. Pendidikan dasar menjadi awal atau permulaan yang akan ditempuh seseorang sebelum mengenyam pendidikan menengah dan selanjutnya. Proses pendidikan tersebut akan berdampak terhadap peradaban masyarakat dalam suatu bangsa.

Perkembangan peradaban bangsa harus ditunjang oleh kemajuan dibidang pendidikan. Pendidikan menjadi faktor terbaik dalam membangun peradaban tersebut. Kurikulum pendidikan, semestinya harus mampu menghasilkan output yang sesuai dengan kebutuhan zaman. Oleh karena itu, pemerintah berusaha untuk terus memperbaiki dan mengembangkan kurikulum demi tercapainya tujuan pendidikan. Pada tahun 2013, kurikulum pendidikan di Indonesia mengalami pergantian setelah menerapkan Kurikulum Tingkat Satuan Pendidikan Tahun 2006 selama kurang lebih selama 7 tahun.

Kurikulum 2013 diharapkan dapat mempersiapkan peserta didik sebagai bangsa Indonesia untuk mampu menghadapi tantangan zaman kedepannya. Jika sebelumnya peserta didik hanya dituntut untuk mengembangkan kompetensi diranah kognitif (pengetahuan), namun pada kurikulum 2013 ini ada 3 standar kompetensi lulusan yang harus dicapai yaitu pada dimensi sikap, pengetahuan dan keterampilan. Peserta didik diharapkan memiliki kompetensi yang yang terkualifikasi sesuai dengan kompetensi lulusan yang telah ditetapkan. Adapun kompetensi lulusan $\mathrm{SD} / \mathrm{MI} / \mathrm{SDLB} /$ Paket A memiliki sikap, pengetahuan, dan keterampilan seperti yang tertuang pada Tabel 1 berikut.

Tabel 1. Kompetensi Lulusan SD/MI/SDLB/Paket A

\begin{tabular}{ll}
\hline Dimensi & \multicolumn{1}{c}{ Kualifikasi Kemampuan } \\
\hline Sikap & Memiliki perilaku yang mencerminkan sikap orang \\
& beriman, berkahlak mulia, berilmu, percaya diri, dan \\
& bertanggung jawab dalam berinteraksi secara efektif \\
& dengan lingkungan sosial dan alam di lingkungan \\
& rumah, sekolah, dan tempat bermain. \\
\hline
\end{tabular}

1 Republik Indonesia, "Undang-Undang No. 20 Tahun 2003 tentang Sistem Pendidikan Nasional” (2003). 


\begin{tabular}{ll}
\hline Pengahuan & Memiliki pengetahuan faktual dan konseptual \\
& berdasarkan rasa ingin tahunya tentang ilmu \\
& pengetahuan, teknologi, seni dan budaya dalam \\
& wawasan kemanusiaan, kebangsaan, kenegaraan, dan \\
& peradaban terkait fenomena dan kejadian di lingkungan \\
& rumah, sekolah, dan tempat bermain. \\
\hline Keterampilan & Memiliki kemampuan pikir dan tindak yang produktif \\
& dan kreatif dalam ranah abstrak dan konkret sesuai \\
dengan yang ditugaskan kepadanya. \\
\hline Sumber: Peraturan Menteri Pendidikan Dan Kebudayaan Republik Indonesia Nomor 54 \\
Tabun 2013.
\end{tabular}

Berdasarkan kompetensi lulusan di atas ada 3 dimensi yang harus dimiliki peserta didik setelah mengenyam pendidikan. Ketiga dimensi tersebut adalah dimensi sikap, dimensi pengetahuan dan dimensi keterampilan. Penilaian dimensi sikap dinilai berdasarkan dua hal yaitu sikap relijius dan sikap sosial.

Perubahan yang mencolok kurikulum adalah dengan adanya pembelajaran Integratif yaitu pembelajaran terpadu dengan menggabungkan kompetensi dasar beberapa mata pelajaran dalam satu tema. Dan hilangnya nama mata pelajaran IPA dan IPS pada kelas rendah (kelas I, II, III SD). Hal tersebut bisa terlihat pada Struktur kurikulum SD $/ \mathrm{MI}^{2}$ di Tabel 2 berikut ini.

\section{Tabel 2. Struktur Kurikulum SD/MI}

\begin{tabular}{|c|c|c|c|c|c|c|}
\hline \multirow{2}{*}{ MATA PELAJARAN } & \multicolumn{6}{|c|}{ ALOKASI WAKTU PER MINGGU } \\
\hline & I & II & III & IV & $\mathrm{V}$ & VI \\
\hline \multicolumn{7}{|l|}{ Kelompok A (Umum) } \\
\hline $\begin{array}{l}\text { 1. Pendidikan Agama dan Budi } \\
\text { Pekerti }\end{array}$ & 4 & 4 & 4 & 4 & 4 & 4 \\
\hline $\begin{array}{ll}\text { 2. } & \text { Pendidikan Pancasila dan } \\
& \text { Kewarganegaran }\end{array}$ & 5 & 5 & 6 & 5 & 5 & 5 \\
\hline 3. Bahasa Indonesia & 8 & 9 & 10 & 7 & 7 & 7 \\
\hline 4. $\quad$ Matematika & 5 & 6 & 6 & 6 & 6 & 6 \\
\hline 5. Ilmu Pengetahuan Alam & - & - & - & 3 & 3 & 3 \\
\hline 6. Ilmu Pengetahuan Sosial & - & - & - & 3 & 3 & 3 \\
\hline \multicolumn{7}{|l|}{ Kelompok B (Umum) } \\
\hline 1. Seni Budaya dan Prakarya & 4 & 4 & 4 & 4 & 4 & 4 \\
\hline $\begin{array}{l}\text { 2. Pendidikan Jasmani, Olahraga, } \\
\text { dan Kesehatan }\end{array}$ & 4 & 4 & 4 & 4 & 4 & 4 \\
\hline Jumlah jam pelajaran per minggu & 30 & 32 & 34 & 36 & 36 & 36 \\
\hline
\end{tabular}

Sumber: Permendikbud Nomor 57 Tabun 2014.

2 Menteri Pendidikan dan Kebudayaan, "Salinan Lampiran I Peraturan Menteri Pendidikan dan Kebudayaan Republik Indoensia Nomor 57 Tahun 2014 Tentang Kurikulum 2013 Sekolah/ Madrasah Ibtidaiyah” (2014). 
Srtuktur Kurikulum SD/MI terdiri atas mata pelajaran umum kelompok A dan mata pelajaran umum kelompok B. Mata pelajaran umum kelompok A merupakan program kurikuler yang bertujuan untuk mengembangkan kompetensi sikap, kompetensi pengetahuan dan kompetensi keterampilan peserta didik sebagai dasar penguatan kemampuan dalam kehidupan bermasyarakat, berbangsa dan bernegara. Mata pelajaran umum kelompok B merupakan program kurikuler yang bertujuan untuk mengembangkan kompetensi sikap, kompetensi pengetahuan dan kompetensi keterampilan peserta didik terkait lingkungan dan bidang sosial, budaya dan seni. Khusus untuk MI, dapat ditambah dengan mata pelajaran keagamaan yang diatur oleh kementerian agama ${ }^{3}$

Dalam mencapai kompetensi lulusan tersebut salah satunya melalui pembelajaran Ilmu Pengetahuan Sosial (IPS). IPS (social studies) pada dasarnya bukan merupakan sebuah disiplin ilmu, namun bisa dikatakan penyederhanaan dari disiplin ilmu-ilmu sosial (sosial sciences) yang dikaitkan dengan masalah-masalah sosial dan diajarkan pada sekolah dasar dan sekolah menengah. IPS dengan ilmu-ilmu sosial sulit untuk dipisahkan karena IPS mengacu kepada Ilmu-ilmu sosial dalam penerapannya baik berupa konsep, pengetahuan maupun teorinya. Tidak semua ilmu-ilmu sosial diturunkan dalam cakupan IPS, tetapi disesuaikan dengan kebutuhan IPS dalam proses pembelajara di sekolah. Hal tersebut berarti bahwa scope bahasan IPS tidak seluas ilmu-ilmu sosial.

Pada Sekolah Dasar (SD), IPS dipelajari oleh kelas tinggi yaitu kelas IV (empat) sampai kelas VI (enam). Sebelum diterapkan Kurikulum 2013, IPS merupakan mata pelajaran yang tersendiri dan terpisah dengan mata pelajaran SD lainnya. Namun pada kurikulum 2013, pembelajaran IPS sudah terintegrasi bersama mata pelajaran lain yang diajarkan secara bertema (tematik). Pembelajaran tematik merupakan pembelajaran yang memadukan beberapa mata pelajaran sehingga terjadi keterpaduan dan mampu memberikan pengalaman pembelajaran bagi peserta didik. Secara sederhana, pembelajaran tematik merupakan suatu proses pembelajaran dengan mengintegrasikan beberapa materi pelajaran dalam satu topik atau yang biasa disebut tema. Dalam proses evaluasi pembelajaran juga terdapat perubahan. Kurikulum 2016 menitik beratkan kepada kognitif dan tes menjadi cara penilaian yang dominan. Sedangkan pada pembelajaran tematik-integrative yang berfokus pada tema

3 Menteri Pendidikan dan Kebudayaan. 
namun penilaiannya berdasarkan proses, menekankan pada aspek kognitif, afektif dan prikomotorik serta penilaian test dan portofolio saling melengkapi. ${ }^{4}$

IPS itu sendiri sebenarnya juga merupakan ilmu yang bersifat tematik atau terintegrasi dalam beberapa disiplin ilmu, sehingga IPS dikatakan sebagai multidisipliner ilmu. IPS memadu beberapa materi dari ilmu-ilmu sosial seperti ekonomi, geografi, sosiologi, sejarah, pendidikan kewarganegaraan, antropologi dan ilmu-ilmu sosial lainnya. IPS dipadu untuk mengkaji fenomena-fenomena sosial yang terjadi di masyarakat secara holistik.

\section{LANDASAN TEORI}

\section{Konsep Kurikulum 2013}

Kebijakan dalam perubahan kurikulum menjadi Kurikulum 2013 dimaksud untuk melengkapi dan menyempurnakan kurikulum sebelumnya. Dalam lampiran Permen Dikbud RI No 57 Tahun 2014, Kurikulum 2013 bertujuan untuk mempersiapkan manusia Indonesia agar memiliki kemampuan hidup sebagai pribadi dan warga negara yang beriman, produktif, kreatif, inovatif, dan afektif serta mampu berkontribusi pada kehidupan bermasyarakat, berbangsa, bernegara, dan peradaban dunia. ${ }^{5}$

Upaya Kurikulum 2013 menjadikan warga negara Indonesia memiliki sikap, pengetahuan dan keterampilan yang mencerminkan good citizen. Sehingga Negara Indonesia memiliki warga negara yang mumpuni dalam bersaing secara lokal maupun global. berikut ini.

Kurikulum 2013 dirancang dengan karakteristik sebagai

1. Mengembangkan keseimbangan antara sikap spiritual dan sosial, pengetahuan, dan keterampilan serta menerapkannya dalam berbagai situasi di sekolah dan masyarakat;

2. Menempatkan sekolah sebagai bagian dari masyarakat yang memberikan pengalamanan belajar agar peserta didik mampu

4 Susilawati Susilawati dan Syaripah Syaripah, "Analisis Pelaksanaan Evaluasi Pembelajaran Berbasis Tematik di Madrasah Ibtidaiyah Kabupaten Rejang Lebong," AR-RIAYAH: Jurnal Pendidikan Dasar 3, no. 1 (21 Juni 2019): 1-22, https://doi.org/10.29240/jpd.v3i1.806.

5 Menteri Pendidikan dan Kebudayaan, Salinan Lampiran I Peraturan Menteri Pendidikan dan Kebudayaan Republik Indoensia Nomor 57 Tahun 2014 Tentang Kurikulum 2013 Sekolah/ Madrasah Ibtidaiyah. 
menerapkan apa yang dipelajari di sekolah ke masyarakat dan memanfaatkan masyarakat sebagai sumber belajar;

3. Memberi waktu yang cukup leluasa untuk mengembangkan berbagai sikap, pengetahuan dan keterampilan;

4. Mengembangkan kompetensi yang dinyatakan dalam bentuk kompetensi inti kelas yang dirinci lebih lanjut dalam kompetensi dasar mata pelajaran;

5. Mengembangkan kompetensi inti kelas menjadi unsur pengorganisasi (organizing elements) kompetensi dasar. Semua kompetensi dasar dan proses pembelajaran dikembangkan untuk mencapai kompetensi yang dinyatakan dalam kompetensi inti;

6. Mengembangkan kompetensi dasar berdasarkan pada prinsip akumulatif, saling memperkuat (reinforced) dan memperkaya (enriched) antar-mata pelajaran dan jenjang pendidikan (organisasi horizontal dan vertikal). ${ }^{6}$

Melalui kurikulum 2013, peserta didik diharapkan memiliki keseimbangan dalam sikap, pengetahuan dan keterampilan yang akan diterapkan dalam kehidupannya. Ketiga dimensi tersebut dikembangkan melalui Kompetensi Inti (KI) yang kemudian dirinci dalam Kompetensi (KD) dari masing-masing mata pelajaran. KD tersebut bekerja secara akumulatif yaitu menghimpun $\mathrm{KD}$ dari setiap matapelajaran, kemudian saling memperkuat dan memperkaya antar mata pelajaran dan antar jenjang pendidikan, sehingga tercapai pendidikan yang berkesinambungan dan bermakna.

\section{Ilmu Pengetahuan Sosial}

Sosial studies atau IPS merupakan program pembelajaran yang bertujuan untuk membantu dan melatih anak didik agar mampu memiliki kemampuan untuk mengenal dan menganalisis suatu persoalan dan berbagai sudut pandang secara komprehensif. ${ }^{7}$ Melalui IPS peserta didik diajarkan agar mampu mengenal fenomena-fenomena yang terjadi di lingkungan baik dari aspek ekonomi, geografi, sosiologi, sejarah dan aspek kajian IPS lainnya.

6 Menteri Pendidikan dan Kebudayaan.

7 Dadang Supardan, Pembelajaran Ilmu Pengetahuan Dasar; Perspektif Filosofi dan Kurikulum (Jakarta: Bumi Aksara, 2015). 
Barr, Barth \& Shemis juga mengemukakan pengertian social studies atau IPS sebagai berikut ini.

"Social studies is an integration of social sciences and bumanities for the purposes of intruction in citizenship education. We emphasize "integration" for social studies is the only field which deliberately attempts to draw upon, in an integrated fashion, the data of the social sciences and the insight of bumanities. We emphasize 'citizenship' for social studies, despite the different in orientation, outlook, purpose and methods of teachers, is almost universally perceived as preparation for citizenship in a democracy".

Jelas dinyatakan bahwa IPS merupakan integrasi dari ilmuilmu sosial dan humaniora yang bertujuan untuk memberikan pengantar pendidikan agar peserta didik menjadi warga negara yang baik (good citizenship). IPS menjadi sebuah integrasi yang digunakan untuk memadukan antara data-data ilmu-ilmu sosial dengan kondisi lingkungan yang ada di masyarakat. Meskipun berbeda dalam orientasi, pandangan, tujuan dan metode yang digunakan oleh guru, secara umum IPS bertujuan untuk mempersiapkan warga negara yang demokrasi.

Gunawan menjelaskan bahwa setidaknya ada 4 tujuan mata pelajaran IPS, yaitu sebagai berikut ini.

1. Mengenal konsep-konsep yang berkaitan dengan kehidupan masyarakat dan lingkungannya

2. Memiliki kemampuan dasar untuk berfikir logis dan kritis, rasa ingin tahu, inkuiri, memecahkan masalah dan keterampilan dalam kehidupan sosial.

3. Memiliki komitmen dan kesadaran terhadap nilai-nilai sosial dan kemanusiaan.

4. Memiliki kemampuan berkomunikasi, bekerjasama dan berkompetensi dalam masyarakat yang majemuk, di tingkat lokal, nasional dan global. ${ }^{9}$

Pembelajaran IPS mencoba untuk menghasilkan warga negara yang reflektif, mampu atau terampil dan peduli. Reflektif adalah mampu untuk berfikir kritis dan mampu memecahkan masalah berdasarkan sudut pandangnya dan berdasarkan nilai dan moral yang dibentuk oleh dirinya serta lingkungannya. Terampil dapat

8 Supardan.

9 Rudi Gunawan, Pendidikan IPS; Filosofi, Konsep dan Aplikasi (Bandung: CV. Alfabeta, 2013). 
diartikan mampu mengambil keputusan dalam memecahkan masalah. Peduli adalah mampu atau peka terhadap kehidupan sosial dan melaksanakan hak dan kewajibannya di lingkungan masyarakat ${ }^{10}$.

Melalui pembelajaran IPS di sekolah, peserta didik diharapkan mampu untuk mengenal data, fakta dan konsep yang ada dikehidupan masyarakat dan lingkungannya yang kemudian mereka generalisasikan sebagai refleksi terhadap pembelajaran bermakna yang telah dilakukan. Peserta didik memiliki kemampuan bersikap, berpengetahuan dan terampil dalam menghadapi fenomenafenomena yang terjadi di lingkungannya. Kemampuan peserta didik dalam memcahkan masalah yang ditemui di lingkungannya akan menjadi modal dalam berbaur di lingkungan masyarakat yang majemuk baik secara lokal maupun global.

\section{METODE PENELITIAN}

Penelitian ini menggunakan metode kualitatif, dimana peneliti melakukan library research dalam mengkaji referensi yang relevan dengan topik pembahasan pada artikel ini. Penulis melakukan pengutipan secara langsung maupun tidak langsung terhadap literatur yang digunakan dengan mencantumkan sumber referensi yang dirujuk dalam daftar pustaka.

\section{HASIL DAN PEMBAHASAN}

Integrasi pembelajaran IPS pada kurikulum 2013 pada sekolah dasar terlihat pada pemaduan pembelajaran IPS dengan pelajaran lainnya dalam sebuah tema. Misalnya pada kelas IV semester 1 pada Tema Indahnya Kebersamaan. Sub Tema 1 mempelajari tentang "Keberagaman Budaya Bangsaku" dan akan dilakukan selama enam kali pembelajaran. Pada pembelajaran I, IPS disandingkan dengan pelajaran IPA dan Bahasa Indonesia. Adapun KD IPS nya adalah Mengidentifikasi keragaman sosial, ekonomi, budaya, etnis dan agama di provinsi setempat sebagai identitas bangsa Indonesia; serta hubungannya dengan karakteristik ruang (KI-3). Pada KI-4 diharapkan siswa dapat menyajikan keragaman sosial, ekonomi, budaya, etnis dan agama di provinsi setempat sebagai identitas

10 Rahmad Rahmad, "Kedudukan Ilmu Pengetahuan Sosial (IPS) pada Sekolah Dasar," Muallimuna: Jurnal Madrasab Ibtidaiyab 2, no. 1 (23 Oktober 2016): 67-78, https://doi.org/10.31602/muallimuna.v2i1.742. 
bangsa Indonesia serta hubungannya dengan karakteristik ruang. ${ }^{11}$ KD pada pembelajaran I bisa dilihat pada Gambar I berikut ini.

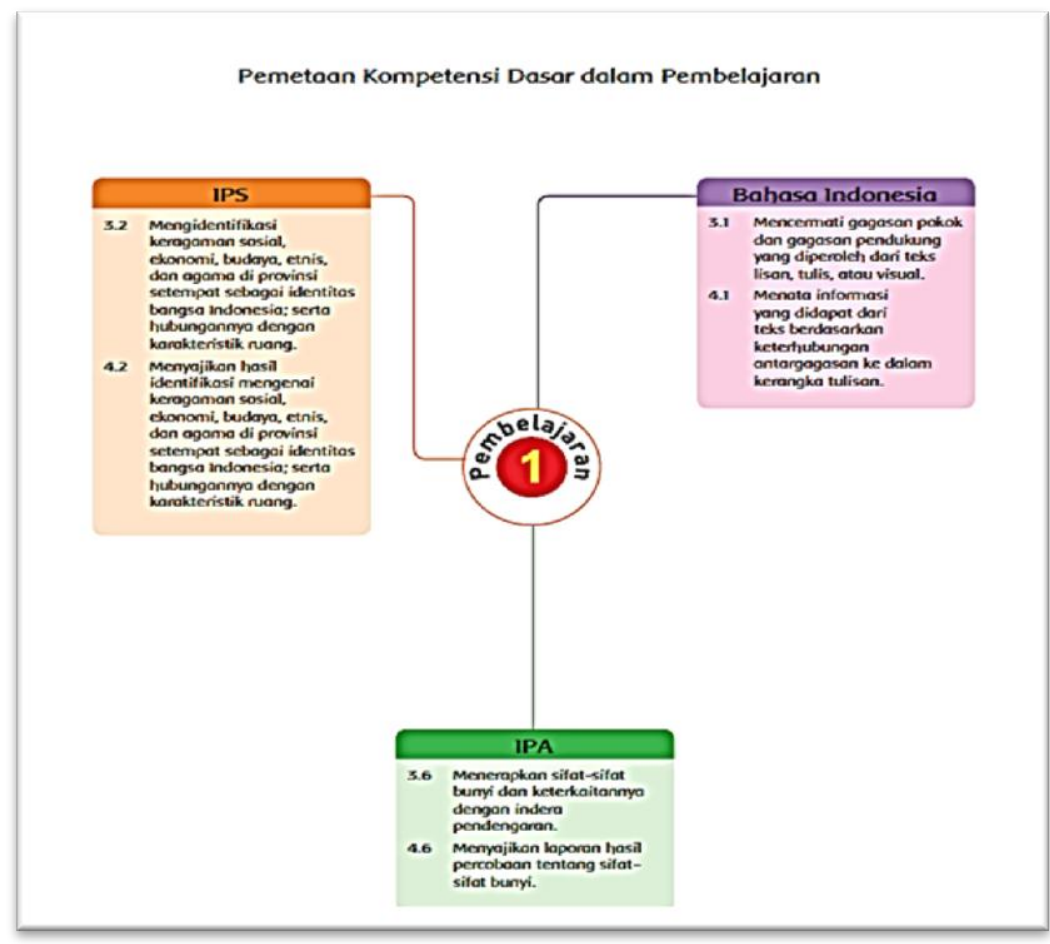

Gambar 1. Pemetaan Kompetensi Dasar Pada Pembelajaran I sub Tema I Tema I

Berdasarkan contoh tersebut terjadi integrasi multidisipliner. Integrasi multidisipliner ini dilakukan tanpa menggabungkan KD tiap mata pelajaran sehingga tiap mata pelajaran masih memiliki Kompetensi Dasarnya sendiri. Sehingga KD IPS masih berdiri sendiri dan tampak jelas tanpa terbaur menjadi KD baru. Pada setiap Tema dan sub tema yang akan dipelajari selalu dipadukan dengan pembelajaran IPS. Setiap sub tema dicapai melalui beberapa kali proses pembelajaran.

Selain itu pendekatan yang digunakan adalah pendekatan intradisipliner, interdisiplir. Integrasi intradisipliner dilakukan dengan cara mengintegrasikan dimensi sikap, pengetahuan, dan keterampilan menjadi satu kesatuan yang utuh disetiap mata pelajaran. Intergrasi interdisipliner dilakukan dengan menggabungkan KD beberapa mata pelajaran agar terkait satu

11 Angi St. Anggari dkk., Indahnya Kebersamaan: Buku Tematik Terpadu Kurikulum 2013 Buku Guru SD/MI Kelas IV, Revisi 2017 (Jakarta: Kementerian Pendidikan dan Kebudayaan, 2017). 
dengan yang lainnya, sehingga dapat memperkuat, menghindari terjadinya tumpang tindih dan menjaga keselarasan pembelajaran. ${ }^{12}$

Integrasi pembelajaran IPS baik secara multidisipliner, intradisipliner dan interdisipliner dengan mata pelajaran lainnya dapat memberikan keterkaitan yang utuh antara setiap mata pelajaran yang diikat dalam sebuah tema yang terpadu sehingga dapat memberikan pembelajaran yang bermakna bagi peserta didik. IPS menjadi penyeimbang dan sesuai dengan kondisi yang ada di lingkungan sekitar secara kontekstual.

Pada kelas rendah (kelas I, II dan III) KD Mata Pelajaran IPS diintegrasikan ke Kompetensi Dasar mata pelajaran Bahasa Indonesia, ke Kompetensi Dasar Mata Pelajaran Pendidikan Pancasila dan Kewarganegaraan, dan ke Kompetensi Dasar Mata Pelajaran Matematika. Sedangkan untuk kelas tinggi (kelas IV, V, dan VI) KD Mata Pelajaran IPS berdiri sendiri, sehingga pendekatan integrasinya adalah multidisipliner, walaupun pembelajarannya tetap menggunakan tematik terpadu. ${ }^{13}$

Pada kelas rendah nama mata pelajaran IPS ditiadakan, namun diintegrasikan IPS diintegrasikan ke dalam KD mata pelajaran lainnya seperti Bahasa Indonesia, Pendidikan Kewarganegaraan, dan Matematika. Jadi secara ruh pembelajaran IPS masih ada namun diintegrasikan pada KD mata pelajaran lain yang dikaitkan melalui keterdekatan makna. Pada kelas tinggi, IPS memiliki kedudukan yang sama dengan mata pelajaran lain. Meskipun pembelajaran dilakukan secara tematik, namun KD untuk IPS tetap berdiri sendiri.

Integrasi Kompetensi Dasar IPA dan IPS di kelas rendah, didasarkan pada keterdekatan makna dan konten Kompetensi Dasar IPA dan IPS dengan konten Pendidikan Agama dan Budi Pekerti, PPKn, Bahasa Indonesia, Matematika, serta Pendidikan Jasmani, Olahraga dan Kesehatan yang berlaku untuk kelas I, II, dan III. sedangkan untuk kelas IV, V dan VI, Kompetensi Dasar IPA dan IPS berdiri sendiri dan kemudian diintegrasikan ke dalam tema-tema yang ada untuk kelas IV, V dan VI. ${ }^{14}$

Integrasi pembelajaran IPS pada Kurikulum 2013 di sekolah dasar menjadi bagian yang tidak kalah penting dalam mencapai

12 Menteri Pendidikan dan Kebudayaan, Salinan Lampiran I Peraturan Menteri Pendidikan dan Kebudayaan Republik Indoensia Nomor 57 Tahun 2014 Tentang Kurikulum 2013 Sekolah/ Madrasah Ibtidaiyah.

13 Republik Indonesia.

14 Yulia Siska, Konsep Dasar IPS untuk SD/MI (Garudhawaca, 2016). 
tujuan kurikulum pendidikan. IPS memiliki posisi yang sama dengan mata pelajaran lain dan memiliki keterkaitan satu sama lain serta diajarkan secara integratif.

\section{PENUTUP}

Integrasi pembelajaran IPS pada kurikulum 2013 pada sekolah dasar terlihat pada pemaduan pembelajaran IPS dengan pelajaran lainnya dalam sebuah tema. Pada kelas rendah nama mata pelajaran IPS ditiadakan, namun materi IPS diintegrasikan ke dalam KD mata pelajaran lainnya seperti Bahasa Indonesia, Pendidikan Kewarganegaraan, dan Matematika. Jadi secara ruh pembelajaran IPS masih ada namun diintegrasikan pada KD mata pelajaran lain yang dikaitkan melalui keterdekatan makna. Pada kelas tinggi, IPS memiliki kedudukan yang sama dengan mata pelajaran lain. Meskipun pembelajaran dilakukan secara tematik, namun KD untuk IPS tetap berdiri sendiri.

\section{DAFTAR PUSTAKA}

Gunawan, Rudi. Pendidikan IPS; Filosofi, Konsep dan Aplikasi. Bandung: CV. Alfabeta, 2013.

Menteri Pendidikan dan Kebudayaan. Salinan Lampiran I Peraturan Menteri Pendidikan dan Kebudayaan Republik Indoensia Nomor 57 Tahun 2014 Tentang Kurikulum 2013 Sekolah/ Madrasah Ibtidaiyah (2014).

Rahmad, Rahmad. "Kedudukan Ilmu Pengetahuan Sosial (IPS) pada Sekolah Dasar." Muallimuna: Jurnal Madrasah Ibtidaiyah 2, no. 1 (23 Oktober 2016): 67-78. https://doi.org/10.31602/muallimuna.v2i1.742.

Republik Indonesia. Undang-Undang No. 20 Tahun 2003 tentang Sistem Pendidikan Nasional (2003).

Siska, Yulia. Konsep Dasar IPS untuk SD/MI. Garudhawaca, 2016.

St. Anggari, Angi, Afikri, Dara Retno Wulan, Nuniek Puspitawati, Lely Miftachul Khasanah, dan Santi Hendriyeti. Indahnya Kebersamaan: Buku Tematik Terpadu Kurikulum 2013 Buku Guru SD/MI Kelas IV. Revisi 2017. Jakarta: Kementerian Pendidikan dan Kebudayaan, 2017.

Supardan, Dadang. Pembelajaran Ilmu Pengetahuan Dasar; Perspektif Filosofi dan Kurikulum. Jakarta: Bumi Aksara, 2015. 
Susilawati, Susilawati, dan Syaripah Syaripah. "Analisis Pelaksanaan Evaluasi Pembelajaran Berbasis Tematik di Madrasah Ibtidaiyah Kabupaten Rejang Lebong." AR-RLAYAH: Jurnal Pendidikan Dasar 3, no. 1 (21 Juni 2019): 1-22. https://doi.org/10.29240/jpd.v3i1.806. 